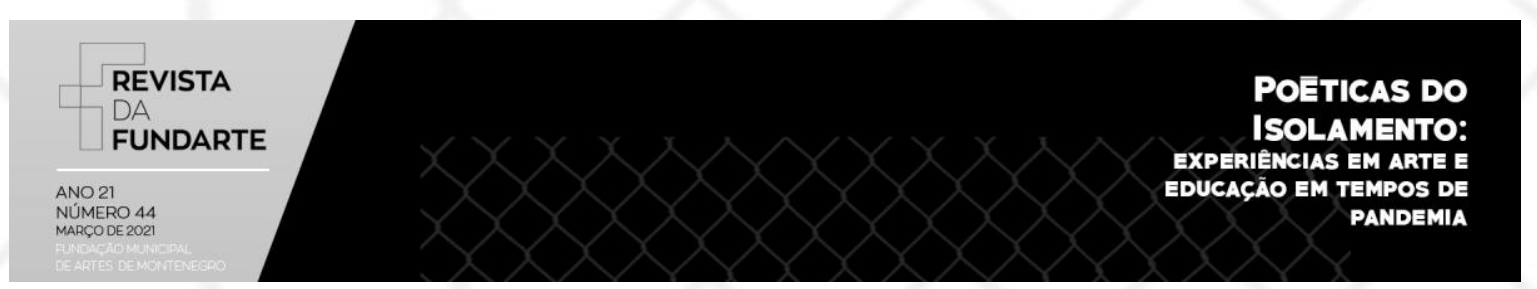

\title{
POLÍTICA DE TAMBORES: TRANSVERSALIDADES QUE MOVIMENTAM UM COLETIVO DE CRIAÇÃO EM MEIO À PANDEMIA DE COVID-19
}

\author{
Francieli Regina Garlet ${ }^{1}$ \\ Vivien Kelling Cardonetti2 \\ Cristian Poletti Mossi ${ }^{3}$ \\ Marilda Oliveira de Oliveira ${ }^{4}$
}

\begin{abstract}
Resumo: Apresentam-se, neste ensaio, indagações e experimentações em forma de escritas e leituras com imagens de um coletivo de criação que se dedica há algum tempo a produzir academicamente com os campos da educação, da arte e da filosofia. Opera-se com os conceitos de percussão e de política de tambores, empreendidos por Basbaum (2017), com a noção de coletivo, abordada por Escóssia (2009) e Escóssia e Kastrup (2005), bem como com a noção de encontro, proposta por Deleuze e Parnet (1998). Do ponto de vista metodológico, aposta-se na noção de transversalidade (GUATTARI, 2004), agenciada por quatro pares de mãos, em revezamento. Buscam-se novas sonoridades, harmonias e melodias na produção científica, em meio a um território traçado entre leituras e escritas com imagens que, na composição deste ensaio, é atravessado também por sons e ruídos de um cotidiano acionado pelo confinamento físico provocado pela pandemia de Covid- 19.
\end{abstract}

Palavras-chave: Coletivo de criação; Política de tambores; Transversalidade.

\section{DRUMS POLICY: TRANSVERSALITIES THAT MOVE A CREATIVE COLLECTIVE IN THE MIDST OF THE COVID-19 PANDEMIC}

Abstract: In this text, questions and experiments are presented in the form of writings and readings with images of a creative collective that has dedicated itself for some time to producing academically

\footnotetext{
1 Pós-doutoranda pelo Programa de Pós-Graduação em Educação da Universidade Federal de Santa Maria (UFSM/RS/Brasil), bolsista PNPD. Mestre e Doutora em Educação, na linha de pesquisa LP4Educação e Artes, Licenciada e bacharel em Artes Visuais todos pela mesma instituição. Membro pesquisador do Grupo de Estudos e Pesquisas em Arte, Educação e Cultura (GEPAECUFSM/RS/Brasil) e do UIVO- Matilha de estudos em criação, arte e vida (UFU/MG/Brasil).

2 Professora Externa do Curso de Graduação à Distância de Educação Especial na Universidade Federal de Santa Maria (UFSM/RS/Brasil). Pós-Doutora pelo Programa de Pós-Graduação em Educação, Linha de Pesquisa LP4-Educação e Artes, da Universidade Federal de Santa Maria. Membro pesquisador do Grupo de Estudos e Pesquisas em Arte, Educação e Cultura (GEPAEC).

${ }_{3}^{3}$ Professor Adjunto da Faculdade de Educação da Universidade Federal do Rio Grande do Sul (UFRGS). Doutor em Educação pelo Programa de Pós-Graduação em Educação (PPGE), na linha de pesquisa Educação e Artes. Mestre em Artes Visuais pelo Programa de Pós-Graduação em Artes Visuais (PPGART), na linha de pesquisa Arte e Cultura, ambos pela Universidade Federal de Santa Maria (UFSM/RS). É membro pesquisador do Grupo de Estudos e Pesquisas em Arte, Educação e Cultura (GEPAEC) e do Grupo de Estudo e Pesquisa em Arte e Docência - ARTEVERSA, ambos vinculados ao CNPq.

4 Professora Titular do Departamento de Metodologia do Ensino, Centro de Educação da Universidade Federal de Santa Maria, (UFSM/ RS/Brasil). Doutora em História da Arte pela Universidad de Barcelona, Espanha. Coordenadora do Grupo de Estudos e Pesquisas em Arte, Educação e Cultura (GEPAEC).
} 


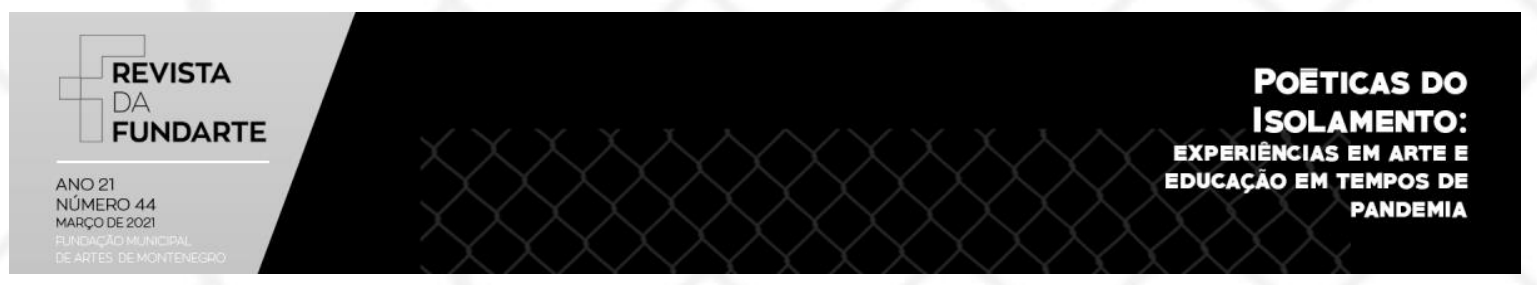

in the fields of education, art and philosophy. The article operates with the concepts of percussion and drums policy, introduced by Basbaum (2017), with the notion of collective, addressed by Escóssia (2009) and Escóssia and Kastrup (2005), as well as with the notion of encounter, proposed by Deleuze and Parnet (1998). From a methodological point of view, the paper adopts the concept of transversality (GUATTARI, 2004), conducted by four pairs of hands, in rotation. New sounds, harmonies and melodies in scientific production are sought, in the midst of a territory drawn between readings and writings with images, which, in the composition of this text, is also crossed by sounds and noises of a daily life triggered by the physical confinement caused by the Covid- 19 pandemic.

Keywords: creative collective; drums policy; transversality.

\section{Paisagens sonoras de um coletivo de criação}

Este ensaio almeja expor parte do processo de experimentação através da escrita e leitura com imagens que os/as autores/as têm se proposto no traçado de um plano de pensamento em ação - um plano de coengendramento (ESCÓSSIA; KASTRUP, 2005) operado em transversalidade (DELEUZE; GUATTARI, 1995; GALLO, 1995; 2006; GUATTARI, 2004; PASSOS; BARROS, 2015), como veremos a seguir -, o qual se configura como um coletivo de criação ${ }^{5}$ que tem se dedicado a produzir academicamente com os campos da educação, da arte e da filosofia, atravessados especialmente por conceitos, perceptos e afectos advindos dessas formas de pensamento/invenção (DELEUZE; GUATTARI, 1992).

Para tanto, nesta escrita operamos com os conceitos de percussão e de política de tambores, empreendidos por Basbaum (2017), com a noção de coletivo, abordada por Escóssia (2009) e Escóssia e Kastrup (2005), e com algumas concepções das filosofias da diferença, mais precisamente com a ideia de encontro, proposta por Deleuze e Parnet (1998). Acerca dessa última, um corpo encontra outro corpo e faz ressoar frequências, pulsações e sonoridades, como violências que mobilizam a criar (escrever, ler, pensar, falar, imaginar...). Esses corpos dizem respeito, neste texto, às pessoas envolvidas em tais processos, mas também aos textos, imagens, ideias, luminosidades, lampejos de cor, sonoridades, entre outras intensidades.

\footnotetext{
${ }^{5}$ Em função da política de avaliação cega por pares, não mencionaremos ao longo do texto o nome do coletivo de criação, para que não acarrete em quebra de anonimato. Contudo, para a versão final do texto, caso aprovado, gostaríamos de incluir seu nome nesta nota de rodapé.
} 


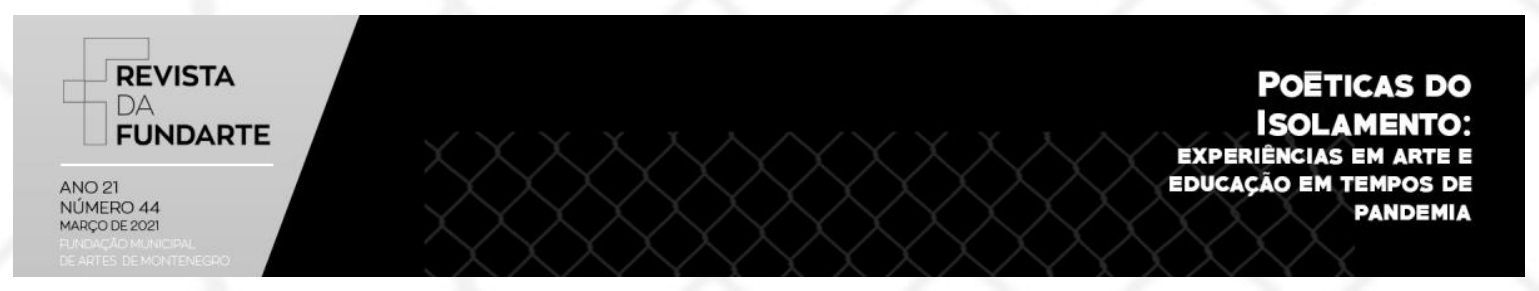

Do ponto de vista metodológico, o ensaio investe, com base nas autoras e nos autores já mencionados e em Guattari (2004), na noção de transversalidade, como vetores intensivos de forças que interferem em um plano que se produz coletivamente, apostando, sempre, na multiplicidade como alastramento de potências a "n" dimensões (DELEUZE; GUATTARI, 1995), que são agenciadas pelos quatro pares de mãos, os quais, em revezamento, escrevem e leem (com sons e imagens).

Entende-se, portanto, que a escrita em revezamento ensaiada pelo coletivo de criação aqui em questão (onde cada par de mãos produz pulsações rítmicas a partir da superfície estendida pelo par de mãos anterior), trata-se, talvez, de uma "política de tambores" (BASBAUM, 2017), que sustenta um modo de vida e produção em docência e pesquisa com educação, arte e filosofia. Essa escritarevezamento tem granjeado a potência no encontro, no estar juntos, no tensionamento da partilha que faz nascer uma pulsação rítmica de criação.

Ao usufruir dessa intensa artesania sonora, os quatro pares de mãos têm experienciado a despersonificação dos autores, abrindo mão de um "Eu" formado, dono da palavra, para entrar em um devir-todo-mundo (DELEUZE; GUATTARI, 2008). Tal criação-sônica-compartilhada tem proporcionado potentes aprendizagens ao ficar frente a frente com alguns desafios, tais como: a incerteza do que está por vir na produção realizada por cada um/a dos/as autores/as, a compreensão que cada par de mãos tem seu tempo de invenção e o emprego de esforços no atravessamento e mistura de vozes, sem que alguma delas entoe mais alto.

Entretanto, essa polifonia não busca um consenso pacificador, pois trata-se, antes, de alianças que arrastam um e outro a traçar/afirmar percursos múltiplos em meio à criação. Ao transitar desta forma, permite-se também compor com o desajuste, com a dissonância. E é essa zona de vizinhança dissonante que tem sido explorada pelos corpos/mãos que compõem o coletivo aqui exposto, atentando para o que essa experiência intensiva pode impelir a conceber, ou seja, para o que os movimentos em meio às palavras, às imagens, às práticas educativas, às pesquisas e à vida podem produzir. 


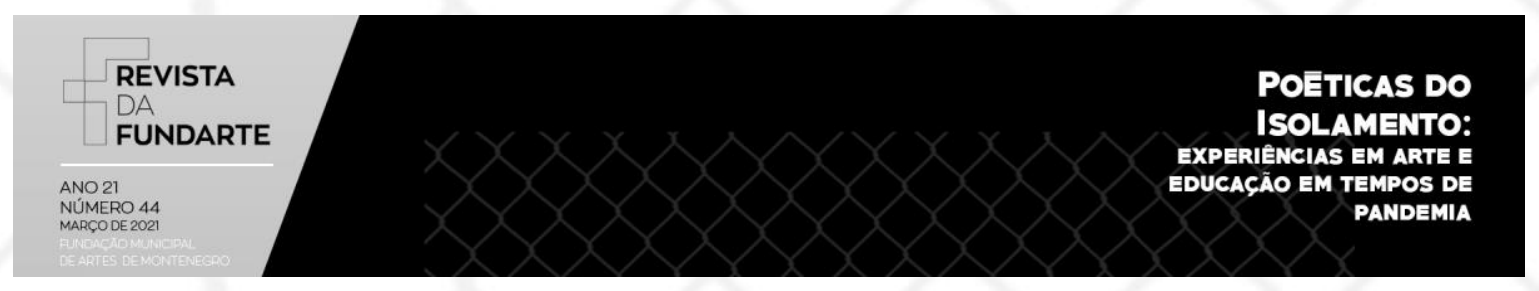

Para tanto, algumas questões mobilizadoras têm acompanhado as produções desse coletivo: Como fazer emergir entre as palavras da escrita acadêmica outras sonoridades? Como povoar as leituras, as escritas e as imagens de possibilidades, distanciando-se da informação, do relato, da representação e daquilo que (nos) faz ecoar sempre em uníssono? Como potencializar escrita/leitura de forma que ela(s) se torne $(\mathrm{m})$ experimentação e o escritor/leitor consiga entoar outros timbres e inflexões desviantes com ela(s) e para além dela(s)? Que ritmos e sonidos podem ser criados e acionados no encontro/entrechoque de corpos-palavras, corposimagens, corpos-existências, corpos-outros?

Escrevemos, portanto, com aquilo que nos convoca a manter um corpo-acorpo com a escrita, com a leitura, com as imagens, com o que mobiliza essas três potências a entrarem em outras possibilidades performativas, possibilidades que nunca se sabem antes do encontro. Encontro, talvez, seja a palavra-chave aqui, pois, é no encontro que corpos-escritas, corpos-imagens, corpos-existências podem perculssionar um ritmo ainda não experimentado, fazendo funcionar, portanto, uma "política de tambores" (BASBAUM, 2017).

A seguir, exploraremos primeiramente os afetos que nos convidam a compor/arranjar este coletivo de criação. Em seguida, trabalharemos com a noção de transversalidade, que não só orienta a metodologia do presente texto, mas também nossos ensaios outros, enquanto coletivo. Finalmente, apresentaremos 0 furto inventor que nos inspira a olhar para o que temos realizado juntos/as, enquanto uma "política de tambores" (BASBAUM, 2017), conforme já explicitado. Deste modo, uma experimentação envolvendo som/imagem/escrita/leitura em meio ao período de isolamento físico/social que temos vivenciado em função da pandemia de Covid-19 fecha o ensaio. Tal experimentação parte do chamado que o dossiê "Poéticas do Isolamento: experiências em arte e educação em tempos de pandemia" nos lança. Assim sendo, as experimentações compostas passam a ser um convite para que as ressonâncias produzidas ecoem para fora do espaço/tempo deste texto. 


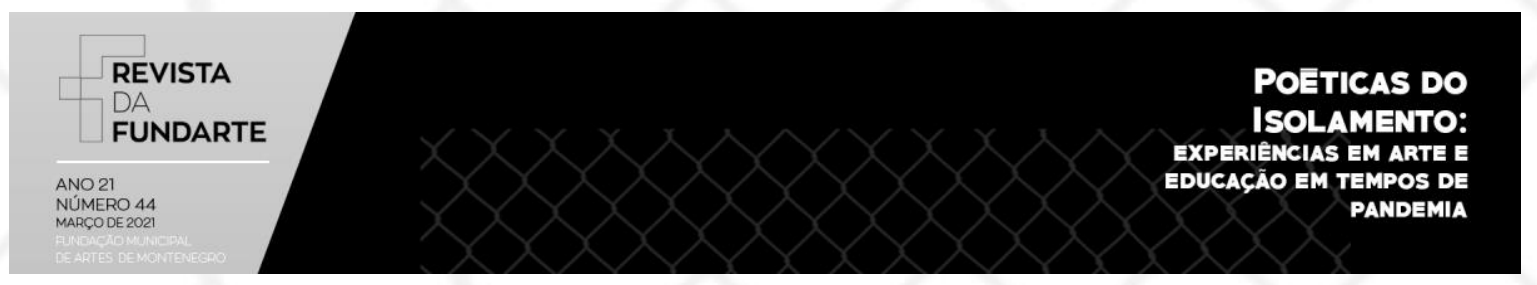

\section{Dos afetos que arranjam um coletivo de criação}

O que se cria no entre de um revezamento de escritas/leituras com imagens, educação, arte e filosofia? Que ritmos surgem nessa percussão? Entre a sobreposição e a justaposição de planos de composição e imanência, que mesclam conceitos, perceptos e afectos? Que sons e ruídos se produzem e são arranjados junto aos corpos-palavras, corpos-imagens, corpos-pensamentos que saltam em meio a esses planos, associado aos movimentos de uma produção acadêmica coletiva?

As questões lançadas possibilitam pensar na potência da pesquisa que tenta se produzir na confluência de movimentos de pensamento de diferentes saberes. Nesse sentido, criar pesquisa em educação

Em meio a uma perspectiva artística e uma perspectiva filosófica, ou em meio ao traçado de um plano de composição e de imanência, supõe não saturá-la de verdades, com coisas a serem devidamente comprovadas, significadas; supõe experimentação de um espaço 'entre' vistos e ditos, intervalo em que nada está dado, onde uma problematização se agita sem respostas que a feche em definitivo. (GARLET, 2018, p. 32).

Antes de nomearmo-nos como um coletivo de criação, já produzíamos coletivamente em meio a esses planos de composição e imanência, participando juntos/as de disciplinas em um Programa de Pós-Graduação em Educação e de grupos de estudos e pesquisas. Participávamos também dos encontros de orientação coletiva, onde nos reuníamos para conversar e pensar as pesquisas de cada um/a.

Esses encontros se davam sempre nesse entre, nesse trânsito com educação, arte e filosofia. Essas três instâncias eram o diapasão que dava a tonalidade do nosso arranjo, e seguiram a nos reunir mesmo quando ficamos distantes fisicamente, em três universidades diferentes do sul do país. Começamos, então, um movimento de escrever juntos/as, em revezamento, num processo de leitura e de escrita com imagens, a quatro pares de mãos. Esse processo, ao mesmo tempo que nos potencializava a inventar um tempo para escrever/ler de

GARLET, Francieli Reginat; CARDONETTI, Vivien Kelling; MOSSI, Cristian Poletti; DE OLIVEIRA, Marilda Oliveira. Revista da FUNDARTE. Montenegro, p.01-19, ano 21, ํo 44, janeiro/março de 2021. Disponível em: http://.seer.fundarte.rs.gov.br/index.php/revistadafundarte/index> 30 de março de 2021. 


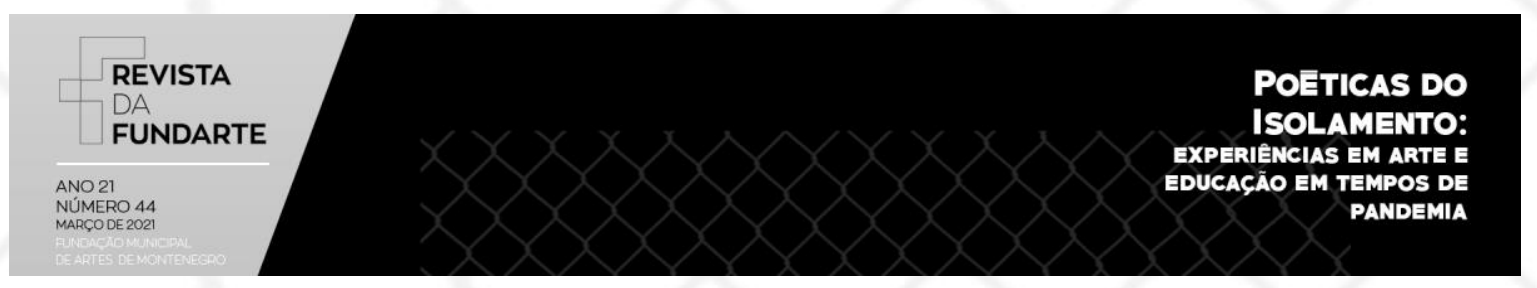

modo potente em meio às atribuições acadêmicas enquanto professores/as dessas instituições de ensino superior, foi um modo, também, de dobrar distâncias e seguir pensando e experimentando as potências de um habitar/produzir num plano de escrita/leitura em multiplicidade.

Operávamos, assim, um coletivo que se aproxima do que Escóssia e Kastrup (2005, p. 296) entendem como "plano de coengendramento e de criação". Uma multiplicidade acionada pelo revezamento entre leitura e escrita com imagens, que nos agencia(va) e arrasta(va) nesse processo, a partir daquilo que nos potencializa(va) junto da leitura e dos escritos dos pares de mãos que pulsa(va)m naquele plano de criação, antes e depois de cada um/a de nós. Em diálogo com Deleuze e Parnet (1998), Escóssia e Kastrup (2005, p. 303) produzem um movimento transversal com o conceito de agenciamento, apontando que

\footnotetext{
Agenciar é estar no meio, sobre a linha de encontro de dois mundos. Agenciar-se com alguém, com um animal, com uma coisa - uma máquina, por exemplo - não é substituí-lo, imitá-lo ou identificar-se com ele: é criar algo que não está nem em você nem no outro, mas entre os dois, neste espaço-tempo comum, impessoal e partilhável que todo agenciamento coletivo revela.
}

Escrever/ler coletivamente diz respeito, portanto, a um agenciamento não só de nós quatro, que nos propomos a escrever/ler em revezamento, mas também de outros elementos que perpassam e que atravessam esse revezamento: imagens, leituras, objetos, sonoridades, outras pessoas, intensidades diversas. E, claro, dos afectos, perceptos e conceitos que vibram e que se movimentam nesses encontros e arranjos invencionados. Ao pensar e produzir com essas dimensões que se agitam nesse plano de coengendramento, talvez seja pertinente questionar: Que outras harmonias e melodias podemos produzir em pesquisa/produção de conhecimento ou em uma escrita acadêmica? Que outras relações sônicas podemos operacionalizar nesse corpo-multiplicidade?

Segundo Deleuze e Guattari (1992, p. 213), os afectos e perceptos são sensações, "seres que valem por si mesmos e excedem qualquer vivido", seres que extrapolam, portanto, as percepções e afecções (sentimentos). Os perceptos "não 


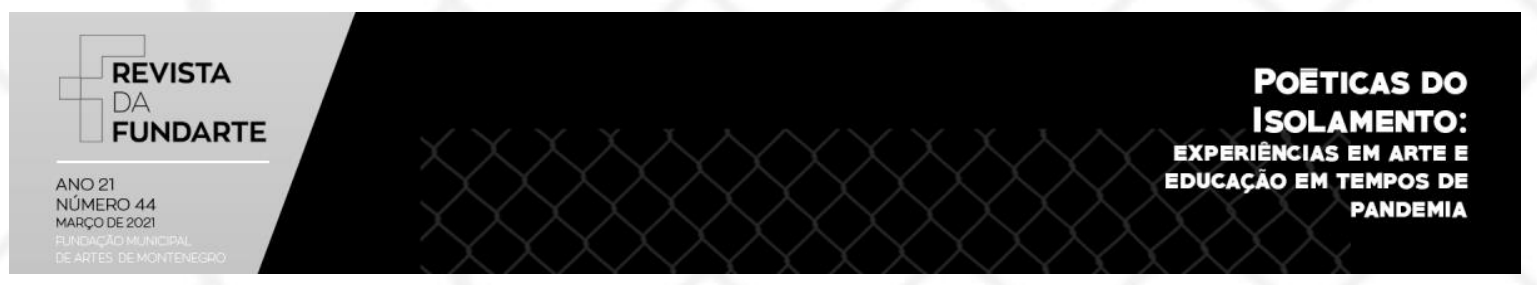

são percepções que remeteriam a um objeto (referência)" e "são independentes do estado daqueles que o experimentam". Os perceptos fazem parte do mundo da arte e essas sensações podem ser visuais, táteis, olfativas, auditivas e gustativas. O que a arte faz é dar durações a essas sensações, ou seja, dá consistência aos perceptos. Os afectos, por sua vez, são "devires não humanos do homem" (DELEUZE; GUATTARI, 1992, p. 220), de forma alguma primam pela semelhança, mas pelo que se cria e produz numa zona de indiscernibilidade em meio ao que se ergue em uma zona de vizinhança. Os conceitos, no seu turno, não são entendidos como enunciados fixos, mas como "monstros que renascem dos seus pedaços" (DELEUZE; GUATTARI, 1992, p. 183), e que para renascer necessitam ser operados, colocados para funcionar com algo. Isto é, os conceitos nos mostram a potência do renascimento junto aos diferentes encontros.

Escrevemos/lemos (com imagens) em agenciamento, como uma estratégia para produzir e/ou fazer vibrar afectos, perceptos e conceitos em meio a essas experimentações, que não seriam possíveis de forma solitária. Operamos, assim, um processo coletivo que não equivale a um "conjunto ou somatório de pessoas. $\mathrm{O}$ coletivo é impessoal, é plano de coengendramento [...]" (ESCÓSSIA; KASTRUP, 2005, p. 303). Um coletivo é produzido em meio a camadas de encontros e contatos, e as oscilações de si também se dão nessas membranas que se produzem a cada vez. Basbaum (2013, p. 260) infere que

[...] entre voz e pele se instaura uma vibrosidade onde as oscilações de si são cortes de um coletivo - e isso é política [...]. Há um ouvido de corpo, mas também um ouvido de grupo - escuta individual e escuta coletiva. Este exercício quer investigar membranas, buscar inscrições para as palavras que tenham o calor do contato. $\mathrm{O}$ calor do contato. $\mathrm{O}$ calor do contato. $\mathrm{O}$ calor do contato. O calor do contato.

O calor do contato produz membranas invisíveis, efêmeras e intersticiais, escutas, entre leituras, escritas, imagens e corpos/pensamentos/pulsações. A criação pode se dar, assim, junto a essa escuta que acontece desde nossos ouvidos de corpo, e que, ao mesmo tempo, produz/inventa/habita ouvidos coletivos. Ouvidos coletivos que sugerem um tato. Ouvidos coletivos com tato - [com]tato, contato. 


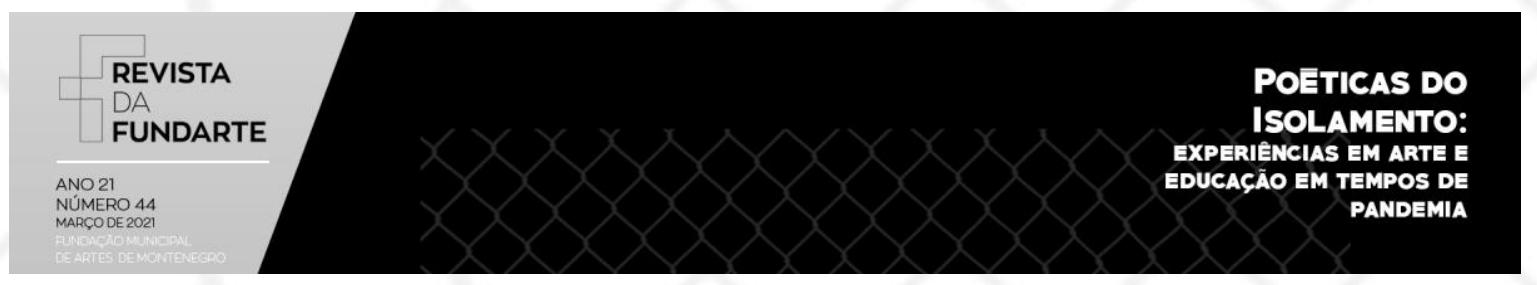

Com tato para a vibração da membrana efêmera produzida no calor de cada encontro. Ouvidos coletivos, que, mesmo ao ouvir o mesmo som, não o reproduzem do mesmo modo, e podem, nesse ruído, produzir escutas dissonantes, criadoras de outros sons, de outros arranjos, outras harmonias e melodias: plurais, em multiplicidade.

Em vista dessas colocações, mais alguns questionamentos podem ser lançados, não para ensaiarmos respostas fixas a eles, mas para seguirmos percutindo a superfície de nossos tambores que se abrem a mais e mais sonidos e indagações: Que inscrições tais escutas (individuais/coletivas) podem produzir a cada vez? Como manter pulsante as intensidades que produzem esse desenho, essa cartografia do som que escutamos/sentimos (com nossos ouvidos de corpos coletivos)? Seria isso produzir e fazer vibrar afectos, perceptos e conceitos em meio à uma escrita acadêmica com educação, arte e filosofia? Seria isso que colocamos em operação enquanto coletivo que escreve, lê, imagina e compõe com/em meio a tais formas de pensamento? A seguir, sondamos possibilidades de arranjos e composições em torno dessas questões, em aliança com a noção de transversalidade.

\section{Movimentos transversais de uma escrita acadêmica coletiva}

A estratégia metodológica que tateamos e exploramos neste ensaio, bem como nas nossas escritas acadêmicas coletivas produzidas ao longo desses anos que nomeamos como um coletivo de criação, aposta na noção de transversalidade (DELEUZE; GUATTARI, 1995; GALLO, 1995, 2006; GUATTARI, 2004, PASSOS; BARROS, 2015). Operar com o movimento transversal nesta e em outras escritas, desafia a exercitar um efetivo movimento de escuta das singularidades que emergem a cada vez que nos deixamos tocar por aquilo que nos chega, pois convoca a pensar na potência da conjugação "e" e nas possibilidades inventivas que dela emergem (DELEUZE; GUATTARI, 1995). Assim, explora a aliança intensiva da conjunção "e" propicia experimentar suas relações de intensidade, mas 


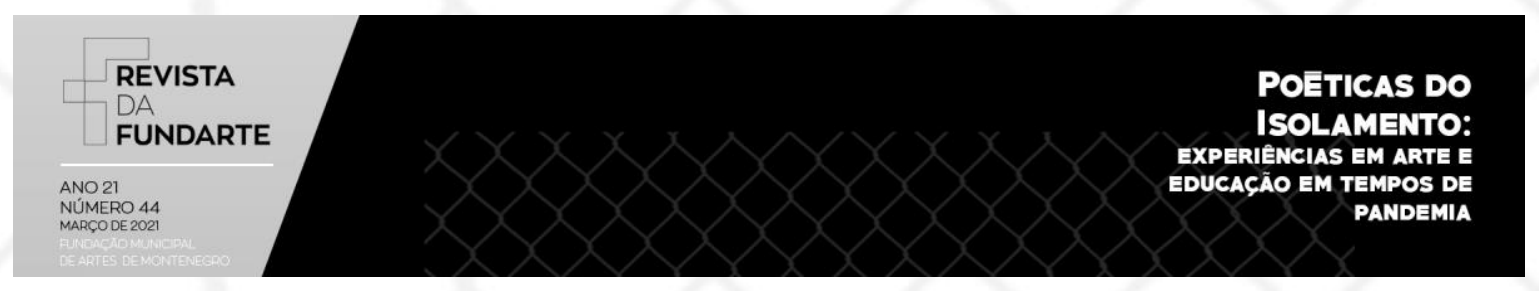

principalmente de implicação. Como colocam Passos e Barros (2015, p. 166), somente com "a abertura do grau de transversalidade seria possível pensar diferentemente".

Guattari (2004) dá um sentido inicial ao conceito de transversalidade no início dos anos 60, nomeando-o como um movimento de abertura comunicacional, de instabilidade dos eixos predominantes de organização da comunicação nas instituições (eixos cartesianos - vertical e horizontal). Para o autor, a transversalidade é uma dimensão que almeja suplantar dois entraves: o da verticalidade pura, na qual tem como premissa a hierarquização da comunicação das diferenças (estrutura piramidal) e o da simples horizontalidade, na qual tem a homogeneização da comunicação na corporação dos iguais.

O conceito de transversalidade atravessa a obra de Guattari e tem ligações com o conceito de rizoma, apresentado mais tarde por ele e por Deleuze, no livro Mil Platôs - Vol. 1. O rizoma é pensado como uma paisagem aberta, na qual um ponto qualquer "pode ser conectado a qualquer outro. É muito diferente da árvore ou da raiz que fixam um ponto, uma ordem" (DELEUZE; GUATTARI, 1995, p. 15), em que a estrutura, a sequência e a evolução estão presentes. No rizoma não existe um centro consolidado a que todos os elementos devem se reportar ou dele se desdobrar, busca-se o descentramento dos envolvidos. Isto é, o fluxo pode seguir qualquer direção, sem nenhuma hierarquia estabelecida previamente.

Em função das inúmeras possibilidades de conexão, adjacências, rompimentos, desvios e percepções, o rizoma solicita uma maneira diferenciada de trânsito, traduzida no movimento transversal. Gallo (1995, p. 10) expõe que a transversalidade "seria a matriz da mobilidade por entre os liames do rizoma", pois somente os movimentos verticais e horizontais "seriam insuficientes para uma abrangência de visão de todo o 'horizonte de eventos' possibilitado por um rizoma".

Gallo (2006, p. 30), a partir dos rastros da filosofia francesa contemporânea, coloca que a transversalidade pode ser vista como um

atravessamento mútuo dos campos de saberes, que a partir de suas peculiaridades se interpenetram, se misturam, se mestiçam, sem no 


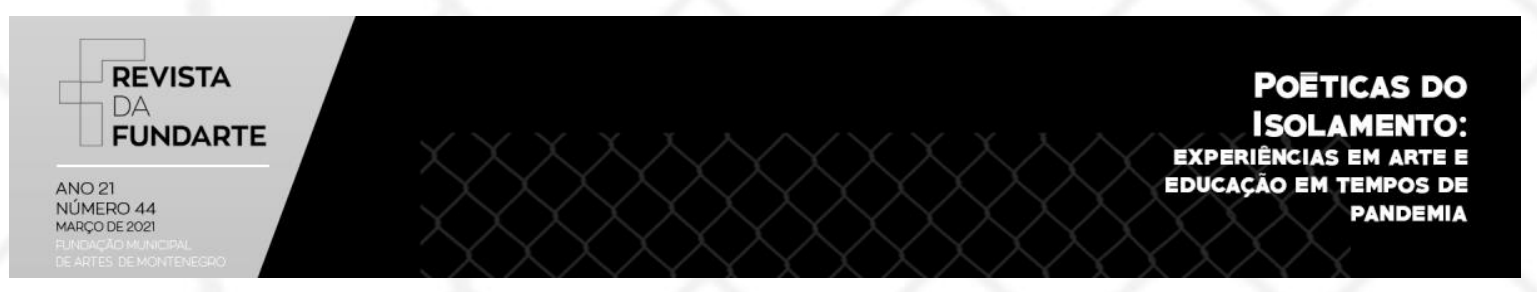

entanto, perder sua característica própria, que só se amplia em meio a essa multiplicidade.

Os movimentos de transversalidade têm atravessado as experiências educativas e investigativas de nosso coletivo de criação, não apenas por permearem as conexões entre elementos heterogêneos, mas, por funcionarem também como um modo operativo de escrita, no qual "não se sabe antes do encontro" (RIBETTO, 2011, p. 110), pois esse está sempre por se fazer, por se esboçar, apagar e redesenhar. Os tensionamentos entre filosofia, arte e educação funcionam como paisagens nas quais pensam-se/operam-se docência e pesquisa em artesania constante. Configuram-se não como territórios fechados e delimitados, mas, como heterogêneos em constante provocação, que arrastam um e outro para outras possibilidades de existir, de soar, ou que fazem cada qual fugir, a cada vez, em seus tensionamentos e problematizações.

$\mathrm{Na}$ seção seguinte, apresentamos a política de tambores como território sonoro por onde nos movimentamos e apostamos na mobilização de conceitos, perceptos e afectos em nossas produções com educação, arte e filosofia. Na sequência, expomos uma breve experimentação realizada recentemente, em regime de isolamento social, desejosos de que as batidas de nossos tambores ecoem em outros espaço-tempos, quiçá provocando alguns abalos.

\section{Percussionar imagens e escritas como política de tambores}

Encontros. Corpos/mãos que escrevem em meio à vida... Coletivo que, em revezamentos, faz funcionar uma potência percussionada (BASBAUM, 2017) a partir de ressonâncias de quatro pares de mãos (atravessadas também por muitos outros corpos/pensamentos/sonoridades) que ensaiam, performam, improvisam escritas/leituras e experiências educativas. E vida, e ensaios, e imagens, "e... e... e..." (DELEUZE; GUATTARI, 1995). 


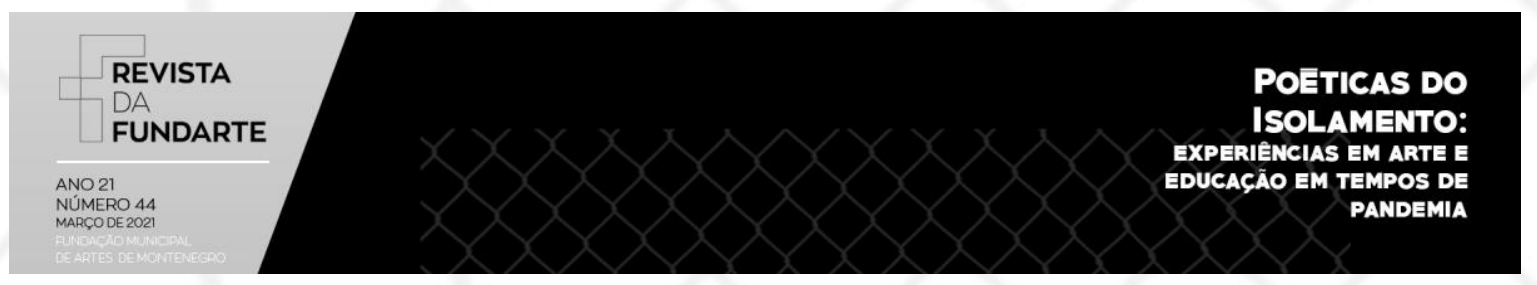

Basbaum fala de uma experiência intensiva proporcionada pelos encontros. No contexto dos seus escritos, esse encontro intensivo se dá entre o corpo da obra de arte e o corpo de quem entra em contato com ela. Nas palavras do autor:

\begin{abstract}
pode-se reconhecer nesse contato algum registro de violência, na medida em que há risco e desejo de transformação com a construção do híbrido ciborgueano obra + corpo, na intensidade do enfrentamento que se registra. Mas sobretudo há aí, no choque do corpo com a obra de arte, a produção de uma sonoridade qualquer, ali presente no espaço de intervenção da obra, elaboração de um momento percussivo a partir do acidente corpo/obra. Qual a pulsação rítmica que percorre aquele ambiente? Como trabalhar a sonoridade desse encontro/embate? Emerge então um espaço propriamente político [...] (BASBAUM, 2017, p. 38).
\end{abstract}

Basbaum opera com a palavra "percussionar" para pensar os encontros entre corpos/pensamento e a arte contemporânea. Entretanto, neste texto, ao modo deleuziano, "roubamos"6 (DELEUZE; PARNET, 1998) este termo, a fim de pensá-lo junto ao que tem nos mobilizado, enquanto coletivo, a criar em meio à vida, em meio às escritas/leituras com imagens e com educação, arte e filosofia.

Basbaum menciona que "onde há ritmo, algo se torna público". Quando algo toca, afeta7, marca um corpo/pensamento, há ressonância, pulsação rítmica no encontro. Podemos afirmar, então, que são as pulsações e as ressonâncias ocasionadas pelos encontros que arranjam essa coletividade de criação do grupo e que mobilizam a invenção de um plano coletivo que se presentifica em produções diversas, nas quais os integrantes vão, ao mesmo tempo em que percutem as superfícies dos textos e imagens em desdobramentos melódicos e harmônicos diversos, modificando-se na pulsação rítmica do revezamento de suas composições enquanto as erigem.

\footnotetext{
6 Um roubo produtivo, como afirmam Deleuze e Parnet $(1998$, p. 6) é acolhido como movimento contrário ao "de plagiar, de copiar, de imitar, ou de fazer como". Ou ainda como menciona Gallo (2003, p. 34) "só se produz na solidão da interioridade, mas ninguém produz do nada, no vazio. A produção depende de encontros, encontros são roubos e roubos são sempre criativos; roubar um conceito é produzir um conceito novo".

$7 \mathrm{O}$ afeto é pensado aqui como variações nas potências de existir que se dão a partir dos encontros (SPINOZA, 2016). Também é entendido como "um modo de pensamento não representativo", ou seja, como algo que aciona devires (DELEUZE, 1976, online).
} 


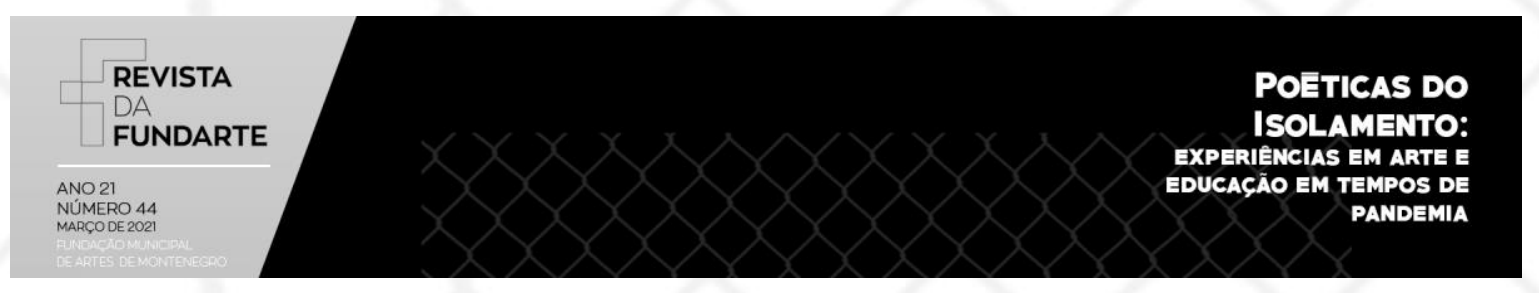

Segundo Basbaum "as rítmicas variam de acordo com os corpos-mentes e sua disposição/disponibilidade" (BASBAUM, 2013, p. 259). Ou seja, podemos nos abrir para os encontros, sermos tocados por eles ou então permanecer indiferentes. Para o autor "toda política é percussiva, isso se dá no sentido de uma política de tambores" num "envolvimento rítmico" onde há "mudanças de andamento e compasso".

Nessa sinfonia percussionada, nessa política de tambores, o que temos produzido são experimentações que não apenas geram um produto, mas, sobretudo, constituem um lugar, um território (sem margens, como um território sonoro), que sustenta uma (de)formação contínua na qual nos singularizamos enquanto pesquisadores/as e professores/as que, com palavras e imagens, produzem efeitos e sentidos com educação, arte e filosofia. Trata-se de um coletivo de criação que, ao experimentar com essas dimensões da escrita, da leitura e das imagens, também se experimenta e convida a experimentar.

O exercício que compõe a seção a seguir foi produzido, assim como o próprio texto deste ensaio, em revezamento. Com o chamado do dossiê "Poéticas do Isolamento: experiências em arte e educação em tempos de pandemia", sentimo-nos instigados a espreitar os sons que atravessam o cotidiano que o contexto da pandemia tem nos forçado a habitar/lidar desde março deste ano (2020). Algumas questões têm nos acompanhado desde então: Que sons têm atravessado nossos dias em isolamento físico na pandemia, e que percussões/sonidos podem ser acionadas ao comporem com imagens e fragmentos de escritas? Como os sons humanos e não humanos produzidos nesse outro cotidiano têm atravessado as paredes da nossa existência em isolamento físico/social?

Fomos convidados/as a espreitar sons audíveis, inaudíveis, ignorados, renitentes e insuportáveis, entre outros. Alguns deles jamais haviam sido ouvidos por nós ou pelo menos não com a mesma intensidade. A reclusão domiciliar nos fez perceber os sons de diferentes modos, em uma outra duração, com uma outra atenção, em sua singularidade.... Mais alguns questionamentos passaram a ser propostos no decorrer desse percurso: O que uma outra temporalidade de escuta e 


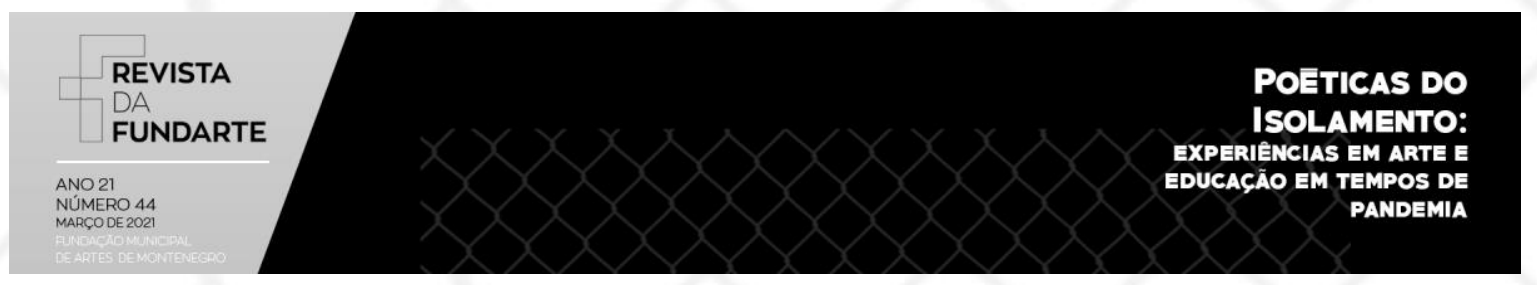

disponibilidade pode produzir com os sons que nos chegam? Que imagens podemos produzir com os ruídos que atravessam nosso cotidiano? O que acontece quando essas imagens são propagadas em um coletivo que escreve junto em meio à uma pandemia como modo de resistir e produzir potências de vida?

Cada um dos pares de mãos que aqui escreve capturou, então, uma imagem a partir de um som que ouviu com frequência no período de isolamento social, vivenciado em função da pandemia de Covid-19, a qual tem nos afetado drasticamente enquanto sociedade desde o início do ano de 2020. Em seguida à produção desses registros, as imagens foram trocadas entre os/as integrantes do coletivo e cada um/a realizou uma escrita curta - uma espécie de aforismo - com/a partir da imagem recebida. A distribuição das imagens também respeitou a ordem de recebimento do presente texto, que foi passando por cada par de mãos o qual, em transversalidade, interferiu em seu conteúdo.

A escolha pela escrita aforística como forma das escritas/leituras breves produzidas a partir das imagens nesta experimentação, está de acordo com o que Dias (2011, p. 29) aponta:

A escritura aforística, por ser a escritura do pensamento que nasceu ao ar livre, é descontínua. Entre um fragmento e outro, há um espaço indeterminado que não separa nem junta os fragmentos. Esse espaço em branco é, para o aforismo, aquilo que a pausa é para a música: um vazio cheio de significação. A fala descontínua e intermitente da escritura aforística deixa vazar para o pensamento a exterioridade. As pequenas histórias, as experiências vividas são elementos que devem entrar no texto, isto é, que o texto agencia para a sua compreensão.

Outro movimento realizado nos revezamentos seguintes de leitura e escrita no coletivo, foi adentrarmos nas pausas dos aforismos e nos intervalos entre os aforismos e as imagens, cartografando ainda algumas percussões acionadas em nosso corpo/pensamento, de modo a agarrar de forma escrita-ensaística fragmentos e passagens de vida em meio aos sons da pandemia. Algumas dessas passagens aparecem na seção seguinte, tanto no arranjo com as imagens, como em itálico no corpo do texto. 


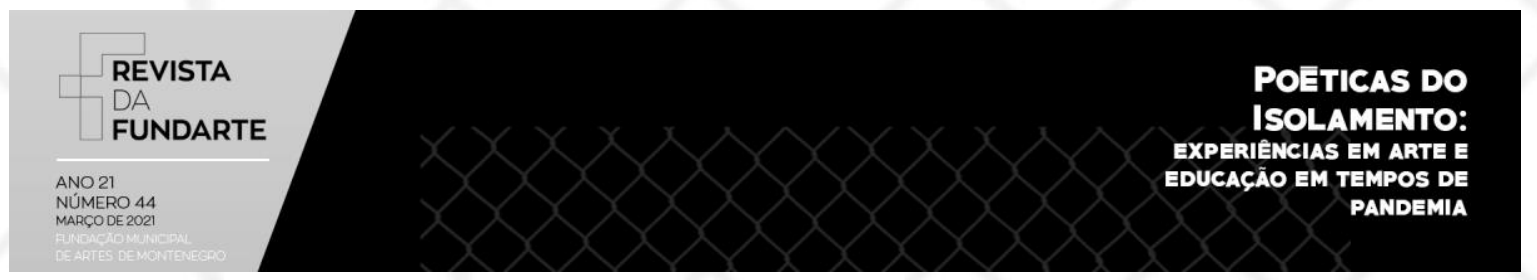

\section{Dos sons que atravessam paredes, janelas, isolamentos... E do que foi possível percussionar com eles}

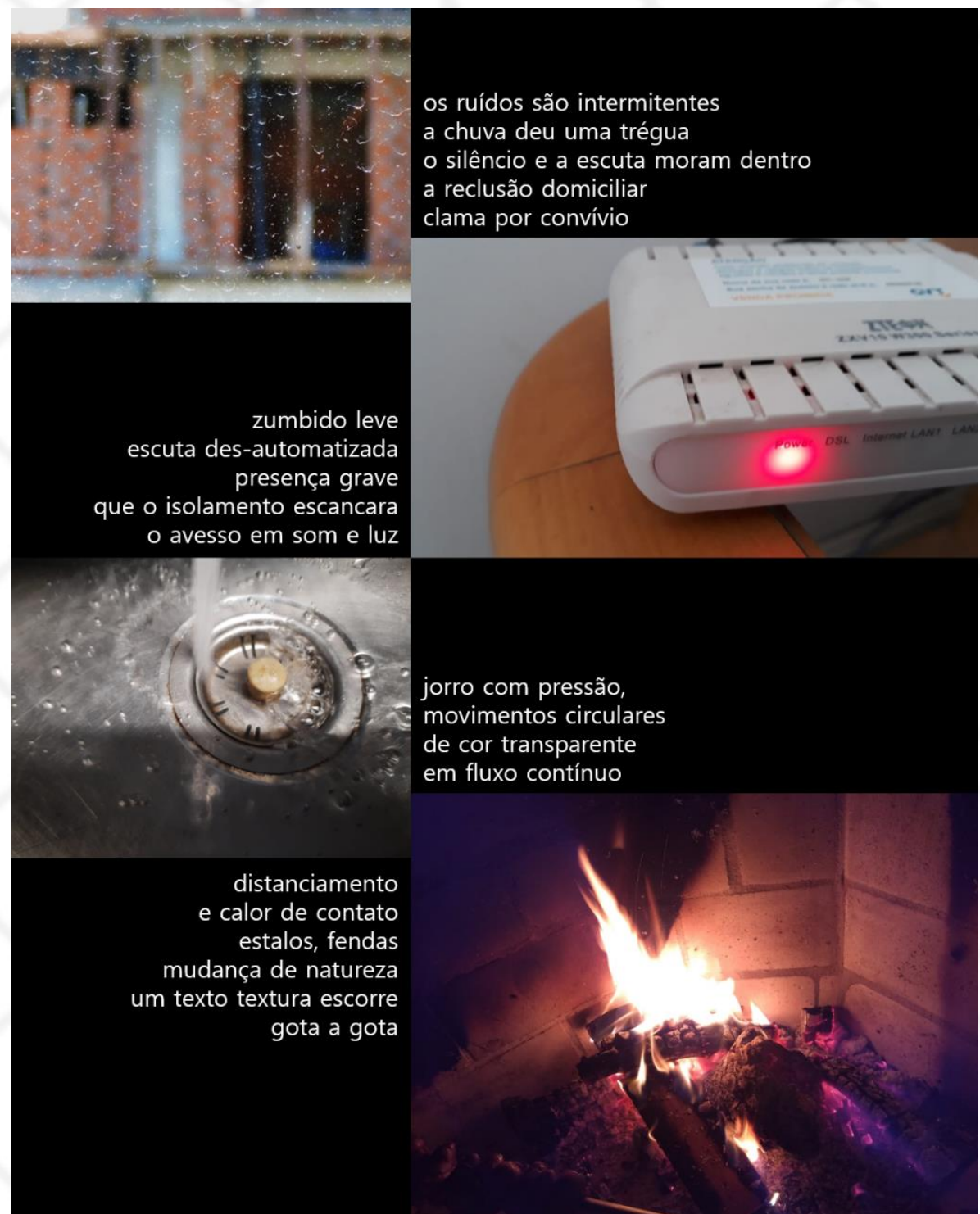

Figura 1: Experimentação com som, imagem e escrita/leitura, arquivo dos/as autores/as (2020).

Dia de desassossego... Desfoque... 


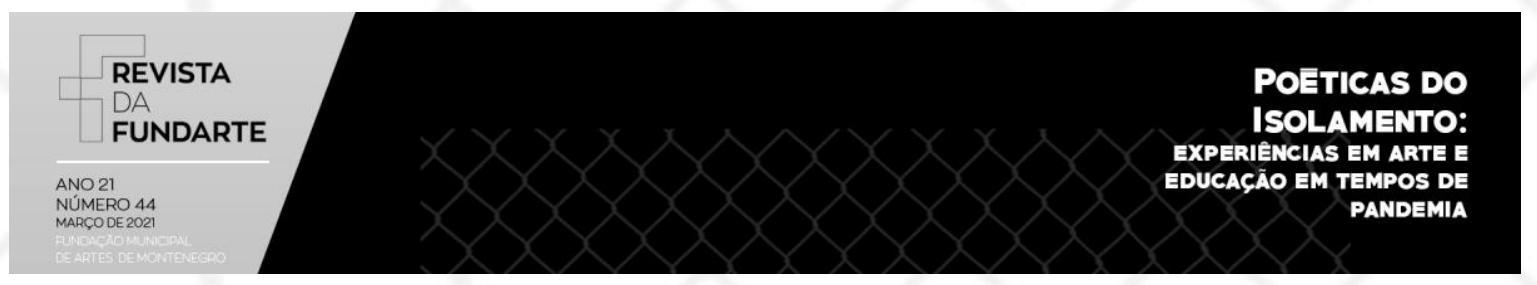

Um convite: captura de som em imagem. Trata-se não de representar um som, mas de apresentá-lo utilizando outra língua, outra conjunção de afetos, traços, passagens, rastros no tempo. Cartografia inexata.

Fazer corpo com um som que pode ser ouvido em isolamento. Fazer imagem e com ela escrever. Escrever para ler e ler para continuar escrevendo. Isolamento. Isolamentos. Lamentos em cor, luz, ruído e movimento de criação. Lamentos no espaço-tempo entre cidades, entre pares de mãos, entre paredes e parênteses.

Deixar que um som afete. Deixar que um som vibre livremente no corpo isolado. Deste ou daquele lado, não importa. O que torna uma experimentação comum?

O vento norte que sopra lá fora faz tremular as janelas e também os olhos já cansados de olhar entre elas (janelas da casa, do computador, do celular)... $O$ vento faz tremular o pensamento e não deixa seguir as linhas retas da leitura... $O$ que quer o vento? Ele quer soprar e só. Música atonal, desviante... Uma certa urgência inquietava o peito naquele dia, um desejo de encontro e de um pouco de arte e de poesia para "inflamar a vida" (VALLE, 2018, p. 20)... Um ruído de furadeira invade a cena. $E$ passa a compor com o ritmo de um reflexo que se agita na parede (ocasionado pelo encontro do copo de água recém acomodado na mesa e o feixe de sol que adentrava pela janela do quarto de estudos/trabalho)...

O confinamento impelido pela pandemia faz entrar em contato também com sons produzidos pelo próprio corpo. Eles dançam e compõem...

Nesse encontro de corpos, diferentes frequências e pulsações rítmicas são produzidas. Desfruta-se dessa intensa artesania sonora dissonante e por alguns instantes entra-se também em composição com ela...

O corpo/pensamento percussionado pelo som da furadeira produz pequenos furos nas paredes cronológicas do tempo e perdura por alguns instantes... Há coisas urgentes para fazer... Empilhadas, com seu peso denso de espera, na superfície do tempo cronológico...

Mas há também outras urgências em batalha, urgências de vida (daquilo que faz a vida pulsar) para as quais tenta-se dar passagem com as palavras que, não sem esforço, atravessaram aqueles pequenos buraquinhos.

Alguns dias se passam...

Captura. Traçado. Ruído desperto de aprendizagem daquilo que o som convoca a pensar. A indagar. Perguntas, perguntas, perguntas e mais perguntas. Um rosário de indagações sem resposta.

O que é a resposta senão um som? Um som que nos obriga a produzir com aquilo que nos desacomoda. A questão também é um som. Mas um som de outra ordem...

Um som que trinca o Eu.

Pensar com o ouvido. Escrever com o ouvido. Ler com o corpo todo que mantém a língua e os olhos extasiados em posição de sobressalto e de vida em estado pueril. Não é possível ignorar a coexistência das percussões de teclas que escrevem com as percussões que produzem paredes que não cessaram de se erguer lá fora, às quais acompanha-se pela janela... 


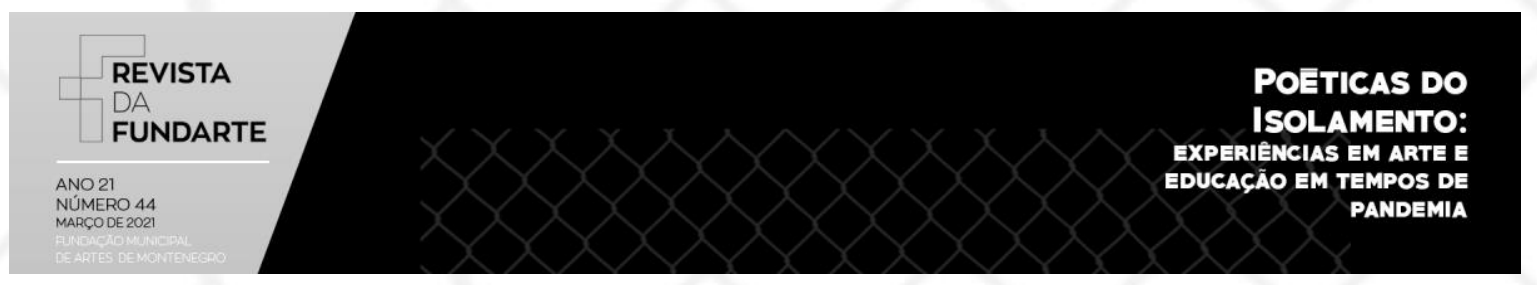

Na membrana que se coloca entre os sons das teclas que escrevem e das paredes que se erguem, há um som inaudível aos ouvidos, qual seria o som emitido pela chuva enquanto seca na vidraça com o sol Vocês ouvem daí?

Ao encerrar essa percussão entre imagens e escritas, mais uma questão insiste em fazer parte, dentre as tantas já enunciadas: Qual a intenção de um coletivo de criação continuar produzindo academicamente com os campos da educação, da arte e da filosofia? Deleuze e Guattari oferecem uma possível resposta, quando eles colocam que "cantar ou compor, pintar, escrever não têm talvez outro objetivo: desencadear (...) devires" (2008, p. 63).

O devir é uma experiência revolucionária, pois manifesta-se na disposição em abdicar de uma circunstância fixada ou infligida, demandando uma energia que impressiona, uma potência inventiva, uma paixão pelo inexplorado. É nesse sentido que os devires nos remetem a uma força que invade e que brota de maneira intensa, é um arrombamento que traz a novidade e não a comprovação, que traz a invenção e não a representação, passando a produzir vestígios de uma vivificação constante. Está entre, em meio, formando blocos que se movimentam e adotam suas próprias linhas, expandindo os heterogêneos por relações de aliança, por contágio.

Os devires disparados junto às experimentações que envolveram sons, ruídos, imagens, palavras e pensamentos, impelem-nos a pensar na potência das experiências limiares e fronteiriças que atuam nas adjacências e nas fendas de um texto acadêmico, quando produzido coletivamente.

\section{Palavras finais que desejam percussões por vir}

Expomos nesse texto um pouco do que tem nos movimentado enquanto coletivo de criação junto à arte, à filosofia e à educação. Tendo como disparador de experimentação nessa escrita a paisagem sonora vivenciada durante o período de isolamento social provocado pela pandemia de Covid-19, buscamos entre leituras, escritas, imagens e em movimentos transversais de revezamento, operar e dar 


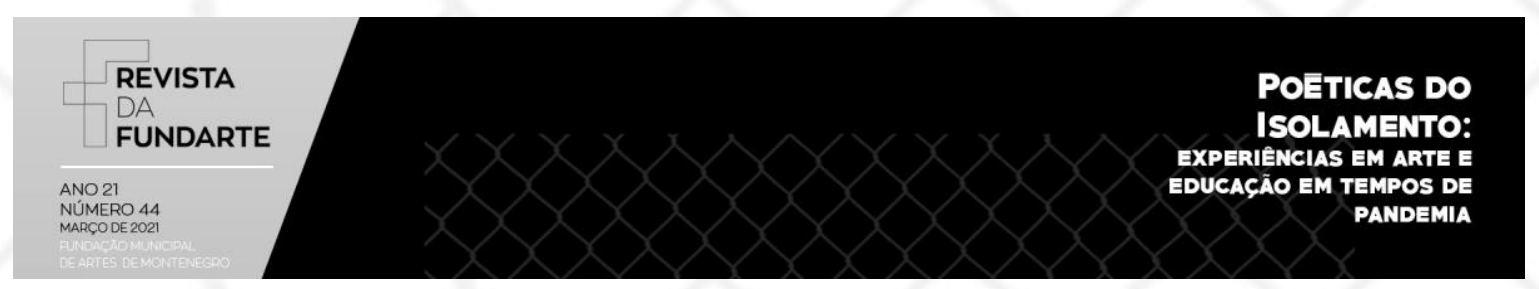

língua às percussões acionadas pela vibração desses encontros. Cada um/a, desde sua casa, foi produzindo esse agenciamento coletivo de criação de possíveis.

De modo algum queremos com tal política, ou com tais experimentações, fundar algum tipo de palavra de ordem para as pesquisas acadêmicas ou para a docência. Nosso intuito conjunto é o de viver possibilidades de criação em um cotidiano universitário que nos exige certa produtividade. A questão para nós é: como viver de outros modos essa exigência, sem nos esquivar dela?

Nessa seara, o exercício aqui apresentado talvez possa ser pensado mais como um convite, como um vislumbre, ou como uma das tantas possibilidades em aliança à uma política de tambores, como aqui a nomeamos. Um convite a fazer junto, a constituir planos coletivos de coengendramento e criação em transversalidade, que atualizem modos de escrever/ler, imaginar e produzir conhecimento entre educação, arte e filosofia. Interessa-nos a polifonia que surge desse encontro de vozes, de ruídos, de variações rítmicas. O que é possível construir com e não sobre.

Nossas problemáticas iniciais, portanto, são de algum modo não contestadas, mas reativadas, na medida que só podem ser respondidas com experimentações que se abrem a outras experimentações. Outras sonoridades são evocadas na escrita acadêmica, apenas enquanto tais sonidos são executados, já que o que buscamos não é a vibração de um grito autoritário, que demanda formas e modelos, mas a sustentação de notas breves, variadas, sincopadas, quase como cantos de pássaros, que são ouvidas somente em composições e arranjos desviantes. Melodias e harmonias ainda a serem ouvidas.

\section{Referências}

BASBAUM, Ricardo. Automatismos e percussões. In: CONDURU, R.; KLABIN, V.; SIQUEIRA, V. B. (Org.). Encontros com a arte contemporânea. Vila Velha, ES: Museu Vale, 2017. p. 24-42.

BASBAUM, Ricardo. Sur, sur, sur, sur... como diagrama: mapa + marca. In: BASBAUM, R. Manual do artista etc. Rio de Janeiro: Beco do Azougue, 2013. p. 241-249. 


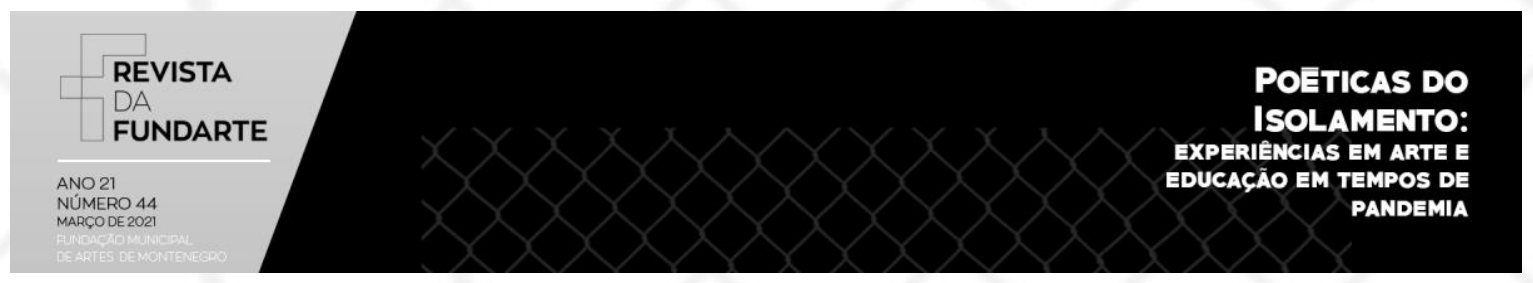

DELEUZE, Gilles; GUATTARI, Félix. O que é a filosofia? Tradução de Bento Prado Junior e Alberto Alonso Muñoz. Rio de Janeiro: Ed. 34, 1992.

DELEUZE, Gilles; GUATTARI, Félix. Mil platôs: capitalismo e esquizofrenia, v. 1. Tradução de Aurélio Guerra e Célia Pinto Costa. Rio de Janeiro: Ed. 34, 1995.

DELEUZE, Gilles; GUATTARI, Félix. Mil platôs: capitalismo e esquizofrenia, v. 4. 4a reimp. Tradução de Suely Rolnik. São Paulo: Ed. 34, 2008.

DELEUZE, Gilles; PARNET, Claire. Diálogos. Tradução de Eloisa Araújo Ribeiro. São Paulo: Escuta, 1998.

DIAS, Rosa. Vida como vontade criadora. In: DIAS, R. Nietzsche, vida como obra de arte. Rio de Janeiro: Civilização Brasileira, 2011. p. 21-82.

ESCÓSSIA, Liliana; KASTRUP, Virgínia. O coletivo como superação da dicotomia indivíduo-sociedade. Psicologia em Estudo, v. 10, n. 2, p. 295-304, 2005. Disponível em: https://www.scielo.br/pdf/pe/v10n2/v10n2a17. Acesso em: 10 set. 2020.

ESCÓSSIA, Liliana. O coletivo como plano de criação na Saúde Pública. Interface Comunicação, Saúde, Educação, v. 13, n. 1, p. 689-694, 2009. Disponível em: https://www.scielo.br/scielo.php?script=sci arttext\&pid=S1414-32832009000500019. Acesso em: 10 jan. 2020.

GALLO, Silvio. Conhecimento, transversalidade e currículo. Programa e resumos da REUNIÃ̃O ANUAL DA ASSOCIAÇÃO NACIONAL DE PÓS-GRADUAÇÃO E PESQUISA EM EDUCAÇÃO (ANPED)., 24, 1995. Disponível em:

http://www.ia.ufrrj.br/ppgea/conteudo/T1SF/Akiko/07.doc Aceso em: 15 dez., 2020.

GALLO, Silvio. Deleuze \& a Educação. Belo Horizonte: Autêntica, 2003.

GALLO, Silvio. A Filosofia e seu Ensino: conceito e transversalidade. Ethica. Rio de Janeiro, v. 13, n. 1, p. 17-35. 2006. Disponível em:

http://professor.ufabc.edu.br/ la.salvia/wp-content/uploads/2016/09/gallo-filosofia-eseu-ensino-conceito-e-transversalidade.pdf. Acesso em: 18 dez., 2020.

GARLET, Francieli Regina. Entre o visível e o enunciável em educação: o que pode uma docência que cava a si mesma?. Tese (Doutorado em Educação). -

Universidade Federal de Santa Maria, Santa Maria/RS, 2018. Disponível em:

https://repositorio.ufsm.br/handle/1/15680. Acesso em: 02 jan. 2021.

GUATTARI, Félix. Psicanálise e transversalidade: ensaios de análise institucional. Aparecida /SP: Ideias \& Letras, 2004. 


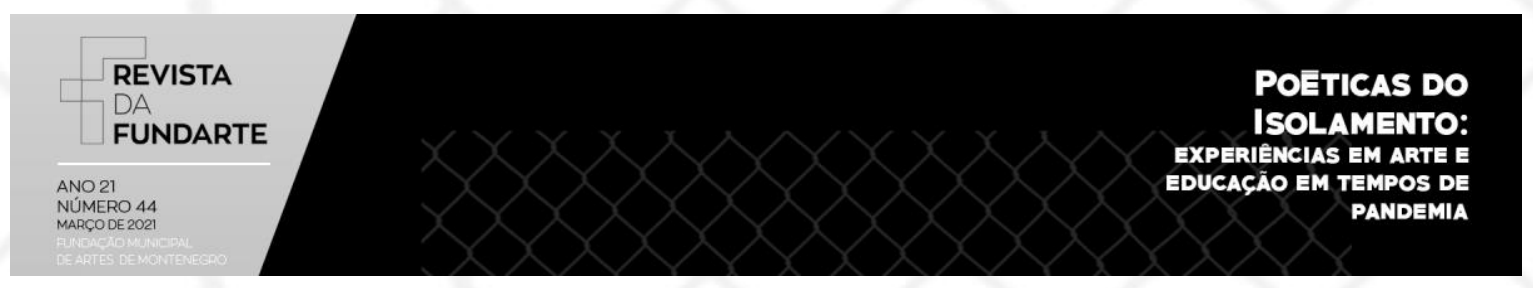

PASSOS, Eduardo; BARROS, Regina Benevides. Por uma política da narratividade. In: PASSOS, Eduardo; KASTRUP, Virgínia; ESCÓSSIA, Liliana (Org.). Pistas do método da Cartografia: pesquisa-intervenção e produção de subjetividade. Porto Alegre: Sulina, 2015. p. 150-171.

RIBETTO, Anelice. Pensar a formação de professores desde a experiência e desde o menor da formação. Reflexão e Ação (versão eletrônica), v. 9, n. 1, p. 109-119, 2011. Disponível em: https://online.unisc.br/seer/index.php/reflex/article/view/2068. Acesso em: 03 jan. 2021.

SPINOZA, Benedictus de. Ética. 2. ed. 5 reimp. Tradução de Tomaz Tadeu. Belo Horizonte: Autêntica Editora, 2016.

VALLE, Lívia Fortuna do. A infância do mundo - escritos para Gilles Deleuze. 2018. Tese (Doutorado em Psicologia). Universidade Federal Fluminense, Rio de Janeiro, 2018. Disponível em:

https://app.uff.br/slab/index.php/busca/formulario completo/1084. Acesso em: 4 dez., 2020. 